\title{
Detailed Effects of a Diesel Particulate Filter on the Reduction of Chemical Species Emissions
}

\author{
Z. Gerald Liu and Devin R. Berg \\ Cummins Emission Solutions \\ James J. Schauer \\ University of Wisconsin-Madison
}

\begin{abstract}
Diesel particulate filters are designed to reduce the mass emissions of diesel particulate matter and have been proven to be effective in this respect. Not much is known, however, about their effects on other unregulated chemical species. This study utilized source dilution sampling techniques to evaluate the effects of a catalyzed diesel particulate filter on a wide spectrum of chemical emissions from a heavy-duty diesel engine. The species analyzed included both criteria and unregulated compounds such as particulate matter $(\mathrm{PM})$, carbon monoxide (CO), hydrocarbons $(\mathrm{HC})$, inorganic ions, trace metallic compounds, elemental and organic carbon (EC and OC), polycyclic aromatic hydrocarbons (PAHs), and other organic compounds. Results showed a significant reduction for the emissions of PM mass, CO, HC, metals, EC, OC, and PAHs.
\end{abstract}

\section{INTRODUCTION}

For many years, diesel engine manufacturers have been working extensively to develop aftertreatment technologies that are capable of significantly reducing the emission levels of each of the primary pollutants which are considered to be a risk to the environment and public wellbeing. The majority of these aftertreatment technologies have been designed with the most consideration being given to compounds such as particulate matter $(\mathrm{PM})$, oxides of nitrogen $\left(\mathrm{NO}_{x}\right)$, carbon monoxide (CO), and hydrocarbons ( $\mathrm{HC})$. However, it is also important to understand what effects these technologies may have on the emission levels of other chemical species which are of toxicological concern, such as certain polycyclic aromatic hydrocarbons (PAHs), aldehydes, and the other species found in Table 1 , due to a variety of physical processes or chemical reactions $[1,2]$.

One primary aftertreatment technology commonly used to reduce the PM emission levels of diesel exhaust is the diesel particulate filter (DPF). There are a variety of DPFs available. For example, the DPF could be made of composite fibrous materials which utilize fine fibers as a means of particle filtration. The DPF may also be an extruded wall-flow monolithic filter, which is commonly made of cordierite or silicon carbide material. The high filtration efficiency exhibited by wall-flow filters is achieved through cake formation on the filter surfaces [3]. As these cake layers collect particles, the overall filtration efficiency of the DPF improves at the cost of increased pressure drop across the filtration media. To reduce this pressure gradient across the filter it is often necessary to remove the cake layer through filter regeneration.

Filter regeneration is a necessary process to maintain continuous operation when a DPF is fully loaded. Regeneration is the process by which the soot deposits on the DPF are removed through oxidation to reduce the pressure drop across the filter. While regeneration can occur passively through reactions involving $\mathrm{O}_{2}$ already

Table 1. List of Mobile Source Air Toxics (MSATs) [4]

\begin{tabular}{|l|l|l|}
\hline Acetaldehyde & $\begin{array}{l}\text { Diesel Particulate Matter + Diesel Exhaust } \\
\text { Organic Gases (DPM + DEOG) }\end{array}$ & MTBE \\
\hline Acrolein & Ethylbenzene & Naphthalene \\
\hline Arsenic Compounds & Formaldehyde & Nickel Compounds \\
\hline Benzene & n-Hexane & POM (See Table 2) \\
\hline 1,3-Butadiene & Lead Compounds & Styrene \\
\hline Chromium Compounds & Manganese Compounds & Toluene \\
\hline Dioxin/Furans & Mercury Compounds & Xylene \\
\hline
\end{tabular}


present in diesel exhaust at high temperatures, it is often necessary to actively initiate the regeneration [1]. Active regeneration may be achieved through hydrocarbon dosing or through electrical heating of the filter elements [1].

The DPF which was used in the present study consisted of a diesel oxidation catalyst (DOC) with dimensions of $26.7 \mathrm{~cm}(10.5 ")$ by $10.2 \mathrm{~cm}$ (4"), which converts NO to $\mathrm{NO}_{2}$ to aid in the process of filter regeneration [1], and a catalyzed soot filter (CSF) with dimensions of $26.7 \mathrm{~cm}$ (10.5") by $22.9 \mathrm{~cm}\left(9^{\prime \prime}\right)$, which provides a high efficiency of PM filtration. Additionally, the catalyst coated DOC and CSF have the further benefit of reducing the emissions of gaseous $\mathrm{CO}, \mathrm{HC}$, and other organics through oxidation to form $\mathrm{CO}_{2}$ and $\mathrm{H}_{2} \mathrm{O}[5,6]$.

Regulatory organizations, such as the U.S. Environmental Protection Agency (EPA) and the California Air Resources Board, have identified a wide range of compounds which may pose considerable risk to the environment and public health. The EPA has developed a list of Mobile Source Air Toxics (MSAT) which contains a variety of compounds including fine particulate matter, aldehydes, and polycyclic organic matter (POM) (see Table 1) [4]. The POM component, found in Table 2, contains 16 species including seven PAHs which have been identified by the EPA as carcinogenic [4].

Table 2. Polycyclic Organic Matter (POM) [4].

\begin{tabular}{|l|l|}
\hline Acenaphthene & Chrysene \\
\hline Acenaphthylene & Dibenz(a,h)anthracene \\
\hline Anthracene & Fluoranthene \\
\hline Benz(a)anthracene & Fluorene \\
\hline Benzo(a)pyrene & Indeno(1,2,3-cd)pyrene \\
\hline Benzo(b)fluoranthene & Naphthalene \\
\hline Benzo(ghi)perylene & Phenanthrene \\
\hline Benzo(k)fluoranthene & Pyrene \\
\hline
\end{tabular}

The compounds found in diesel engine exhaust are typically present in both the gas and particle phases depending upon the chemical composition of the particular species $[1,7]$. Although a significant number of these compounds are considered to be derived from diesel fuel and lubrication oil, previous studies have shown that some species may also result from thermal alteration at high exhaust temperatures, whether found in-cylinder or during aftertreatment system regeneration $[7,8,9,10]$.

The goal of the present study was to perform a comprehensive analysis of the diesel engine exhaust products in order to gain a full understanding of the effects that DPF technology has upon these emissions. The chemical species analyzed included the criteria air pollutants, $\mathrm{PM}, \mathrm{CO}$, and $\mathrm{HC}$, as well as a large variety of particulate and gaseous organic compounds.

\section{EXPERIMENTAL SECTION}

TEST ENGINE, LUBE OIL, AND FUEL - To determine the effects of DPF technology on the emissions of a wide spectrum of chemical species emissions, a heavyduty diesel engine (435 HP), without exhaust gas recirculation (EGR), was tested both with and without the DPF aftertreatment system.

During testing, the engine was lubricated with Shell Rotella $T$ 15W-40. Additionally, the test engine was fueled with certified diesel fuel supplied by Chevron Phillips. The fuel was \#2 certified diesel which was determined to have a cetane number of 47 , a sulfur content of $308.5 \mathrm{ppm}$, a particulate matter content of 0.1 $\mathrm{mg} / \mathrm{liter}$, and an aromatic composition of $29.5 \%$. The experiments for the present study were conducted prior to the implementation of ultra low sulfur diesel (ULSD) in the U.S. Although the test engine and diesel fuel used in the present study did not correspond with current practices, this study did not concentrate on the effects of the engine or fuel content and thus the engine and fuel were used only as sources of chemical pollutants.

TESTING AND SAMPLING PROCEDURE - After warming the test engine for 2 hours at ISO mode 8 (50\% load, intermediate speed), blank samples were collected to check for contamination from the dilution air and handling procedures [11]. During sampling, the engine was operated under the transient Federal Test Procedure (FTP) which simulates typical New York and Los Angeles freeway and non-freeway conditions over a 20 minute cycle [4]. After each FTP cycle, additional blank samples were collected during the remaining testing processes including background, storage, and transportation. Once testing was completed, all samples collected from the source sampling system as well as the blanks were stored and transported in temperature and humidity controlled containers to minimize the effects of external conditions.

The engine was first tested with the DPF in place, and the backpressure was measured and recorded with a data acquisition system. The backpressure was later matched by an electronic restrictor valve while the engine was being operated without the DPF. This ensured that the engine was operating under similar conditions for each testing configuration and reduced the amount of variation between them.

At least three separate samples were collected from the source sampling system for each test configuration to determine the sample variation. The source sampling system utilized a constant volume flow to minimize the effects of variable exhaust gas temperature [12]. As seen in Figure 1, the system consisted of a critical flow venturi-constant volume system (CFV-CVS) primary dilution tunnel, secondary micro-diluter, residence time chamber (RTC), and multiple sampling trains capable of collecting both gaseous and particulate emissions. The entire exhaust flow was introduced into the primary dilution tunnel where it was allowed to thoroughly mix 


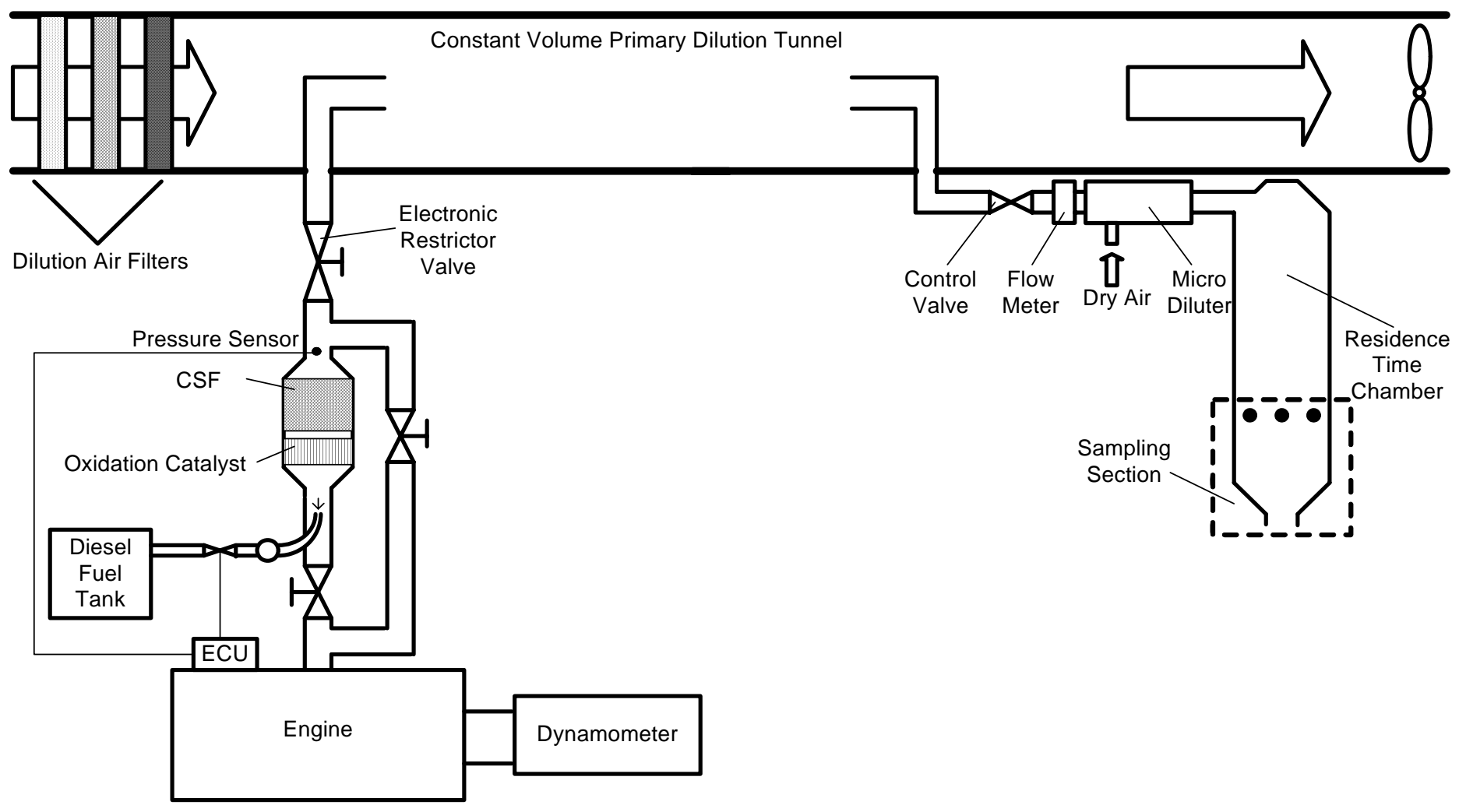

Figure 1. Source Sampling System Used for Sample Collection.

with the pre-cleaned dilution air. By introducing the entire exhaust flow in the primary dilution tunnel, the system is less prone to sampling error than systems which extract a partial sample of the exhaust flow for the primary dilution.

From the CFV-CVS tunnel, a partial sample was extracted by a secondary micro-diluter which was utilized to achieve the final dilution ratio and stabilize the samples. Mixing within the secondary micro-diluter was aided through the use of a static pressure chamber which allowed for uniform distribution of the dilution air.

A residence time chamber was incorporated as part of the source dilution sampling system to optimize the sample partitioning. The RTC allowed for the homogeneous and heterogeneous nucleation of particles to occur. It was determined that a residence time of 30 seconds allowed for the diffusion limited transport of gaseous organics onto existing particles. Additionally, the RTC enabled the exhaust flow to become uniformly distributed before samples were extracted.

The sampling trains were connected to the sampling section of the RTC through isokinetic sampling probes which were aligned with the flow direction and were sufficiently spaced to avoid interference [12]. Each of the sampling probes was made from thin walled stainless steel tubing and the edges of the tubing were sharpened to minimize particle loss due to partial sampling $[13,14]$.
The sampling trains utilized several types of media for the collection of exhaust samples. Particulate samples were collected with quartz and polytetrafluoroethylene (PTFE) filters while gaseous samples were collected using polyurethane foam (PUF) arranged as seen in Figure 2. Further, additional gaseous samples were collected using thermal desorption (TD) tubes and dinitrophenylhydrazine (DNPH) cartridges as seen in Figure 3. The high-volume sampling train, also seen in Figure 3, allowed for the quantification of chemical species which had ultra-low concentrations within the exhaust flow. Lastly, PTFE-coated aluminum $\mathrm{PM}_{2.5}$ cyclones were used upstream of the sampling media to pre-classify PM in the exhaust gases.

ANALYSIS PROCEDURES - Chemical speciation of the collected samples was conducted by the Wisconsin State Laboratory of Hygiene. Particulate emissions such as soot, trace metals, inorganic ions, and particle-phase organics were captured using quartz and PTFE membrane filters which were first weighed for total PM mass before being subjected to a more comprehensive chemical speciation. In order to obtain a mass measurement for the total particulate matter collected from the source dilution sampling system, two separate sets of $47 \mathrm{~mm}$ PTFE membrane filters were weighed in a draft and static free room with a robotic filter weighing apparatus which was certified to 2007 regulations and beyond.

Analysis of elemental and organic carbon (EC and OC) samples in the particulate matter was performed using a thermal-optical method as described by Birch and Cary 
[15]. The samples were first heated to $870{ }^{\circ} \mathrm{C}$ under a helium atmosphere to evolve the $\mathrm{OC}$ that was contained within the sample. The resulting OC sample was then oxidized to $\mathrm{CO}_{2}$ and reduced to methane before being quantified by a flame ionization detector. The sample was then cooled and re-heated in a helium and oxygen atmosphere to remove all carbon from the filter. The evolved carbon was corrected for pyrolysis carbon formed during the initial analysis stage and the elemental carbon in the sample was calculated. The final OC mass measurement was reported as the sum of the carbon evolved during the initial stage of the analysis plus the pyrolysis carbon. Finally, the OC mass measurement was corrected for non-adsorbed gaseous $\mathrm{OC}$ by subtracting the second filter in the series from the first [16]. Additionally, a factor of 1.2 was multiplied by the OC mass to account for the oxygen, hydrogen and nitrogen components. This final mass measurement was then reported as the total organic matter (OM), which was believed to be absorbed onto the particulate EC emissions [17].

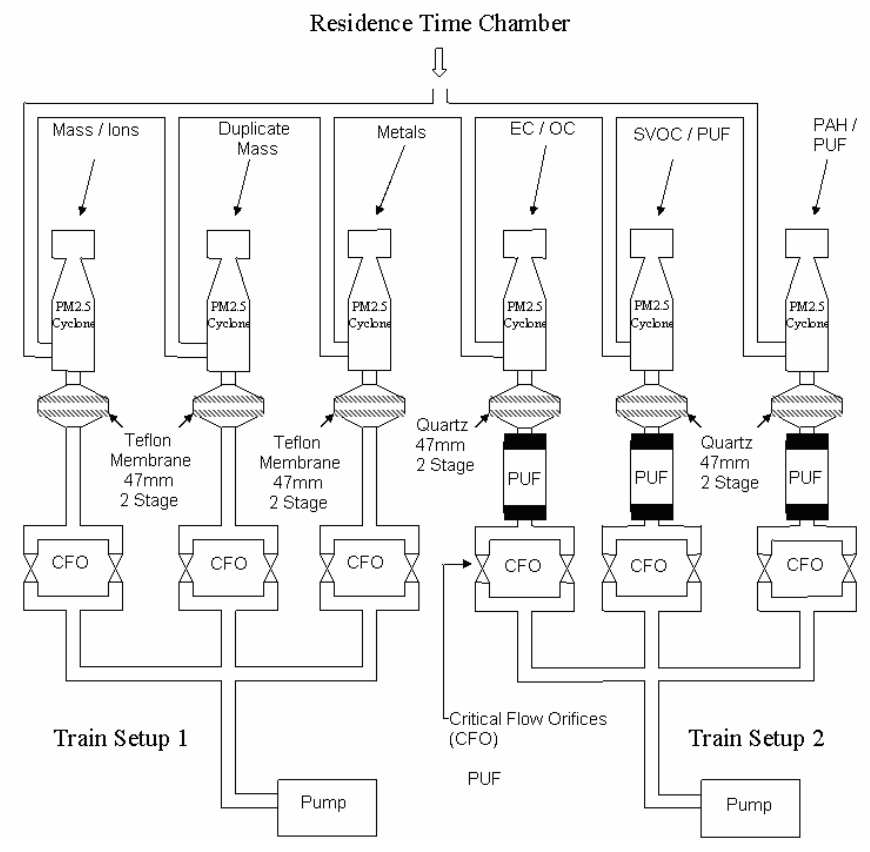

Figure 2. Sampling Train Diagram [12].

Further analysis for particle-phase compounds was performed on the baked quartz filters, PTFE impregnated glass fiber filters, and PTFE membrane filters. Inorganic ionic and trace metallic species were both collected using PTFE membrane filters. One set of filters, to be analyzed for ionic compounds, was extracted in water and then analyzed by ion chromatography [18]. A second set of filters was prepared by extracting the filters in an acidic solution consisting of hydrofluoric, nitric, and hydrochloric acids. The filters were then analyzed for trace metallic compounds by high resolution inductively coupled plasma mass spectroscopy [18].

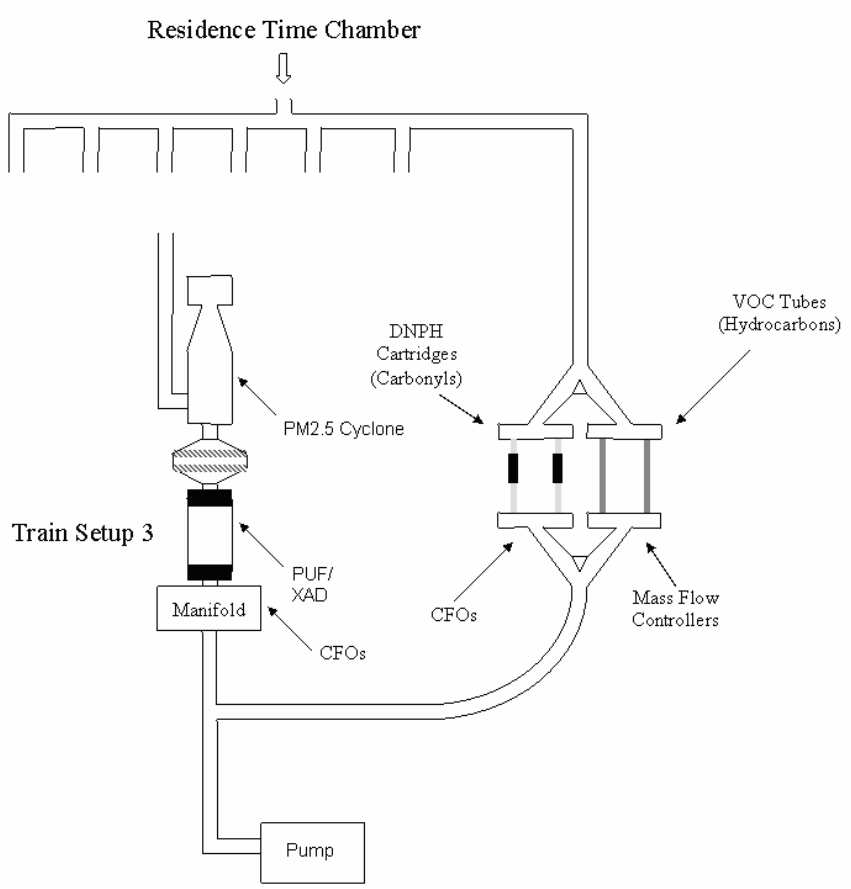

Figure 3. Gaseous and High Flow Sampling Trains [12].

Particulate organic species, collected on quartz and PTFE filters, were analyzed by GC/MS. The quartz filters were baked prior to sample collection at a temperature of $550{ }^{\circ} \mathrm{C}$ for 12 hours to remove any pre-existing organic compounds. The gaseous samples that were collected on TD tubes, PUF cartridges, and DNPH cartridges were analyzed for PAHs, alkanes, and aldehydes using several different methods. TD tubes were analyzed by GC/MS according to a procedure based upon the National Institute of Occupational Safety and Health (NIOSH) 2549 method after being conditioned to ambient temperature and placed into a thermal desorber [19]. PUF cartridges were analyzed together with the quartz filters used for particulate sample collection and were pre-cleaned by solvent extraction. Lastly, DNPH cartridges were analyzed using high performance liquid chromatography after being desorbed with acetronitrile [20].

\section{RESULTS AND DISCUSSION}

CRITERIA POLLUTANT EMISSIONS - Previous studies have suggested that incomplete combustion of the SOF can result in increased emissions of $\mathrm{HC}$ and $\mathrm{CO}$ [6]. However, for the engine equipped with the DPF aftertreatment system, a reduction of $\mathrm{CO}$ and $\mathrm{HC}$ emissions was achieved, most likely due to oxidation over the DOC to form $\mathrm{CO}_{2}$ and $\mathrm{H}_{2} \mathrm{O}[1,5]$.

PM mass emissions were found to be significantly reduced with the use of the DPF aftertreatment system. Results show a filtration efficiency of greater than $98 \%$ for PM mass emissions when using the DPF, which has been achieved in the past $[21,22,23]$. The DPF is believed to reduce PM emissions primarily through particle filtration mechanisms such as interception and 
diffusion aided by thermophoresis and electrophoresis, followed by combustion of the PM as the filter undergoes regeneration [1].

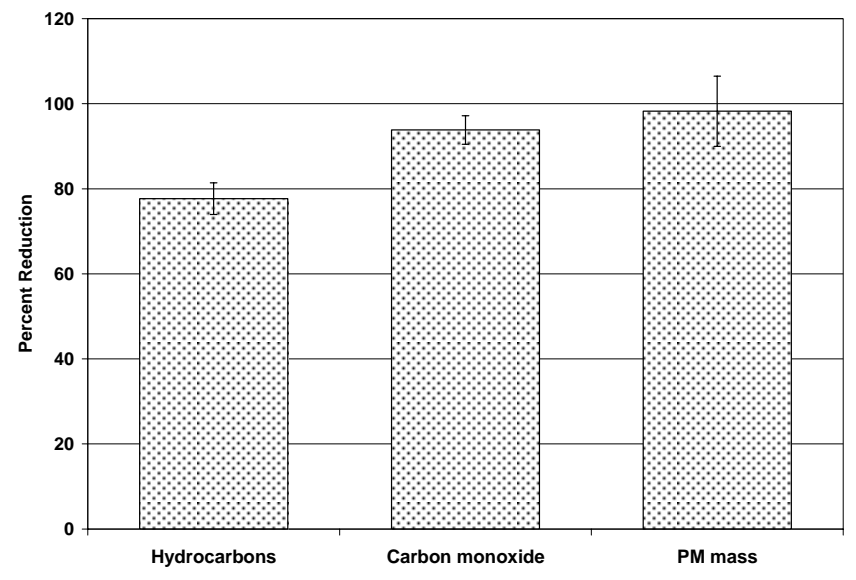

Figure 4. Emissions Comparison for Criteria Air Pollutants.

The major contributors to the total particulate mass included EC, OM, ammonium ion, sulfate ion, sodium ion, and trace metallic compound emissions. EC emissions, commonly known as soot, were found to be reduced significantly, by $\sim 99.7 \%$, with the use of the DPF. EC is present in the particle-phase and is important to consider since the EC particles comprised greater than $45 \%$ of the total PM mass emissions from the baseline engine and often adsorb organic compounds, such as organic carbon and PAHs [16].

Particulate $\mathrm{OM}$, which was calculated through the quantification of $\mathrm{OC}$ emissions, consisted primarily of organic material adsorbed to the particle-phase EC. Therefore, the emission reduction of $\sim 93.5 \%$ displayed by OM mass emissions was expected due to the correlation with particulate EC emissions. Significant reductions of metallic compounds across a DPF have also been reported in the past [22]. The percent reductions for each of these compounds from the present study can be found in Figure 5, which shows that the majority were significantly reduced by the DPF aftertreatment system. The remaining contributors to the total PM mass included inorganic ionic species and particulate organic emissions. The inorganic ions which were quantifiable under the present analysis methods included the ammonia, sulfate, and sodium ions and were found to reduce significantly through the use of the DPF. Particulate organic emissions will be discussed in detail in the next section.

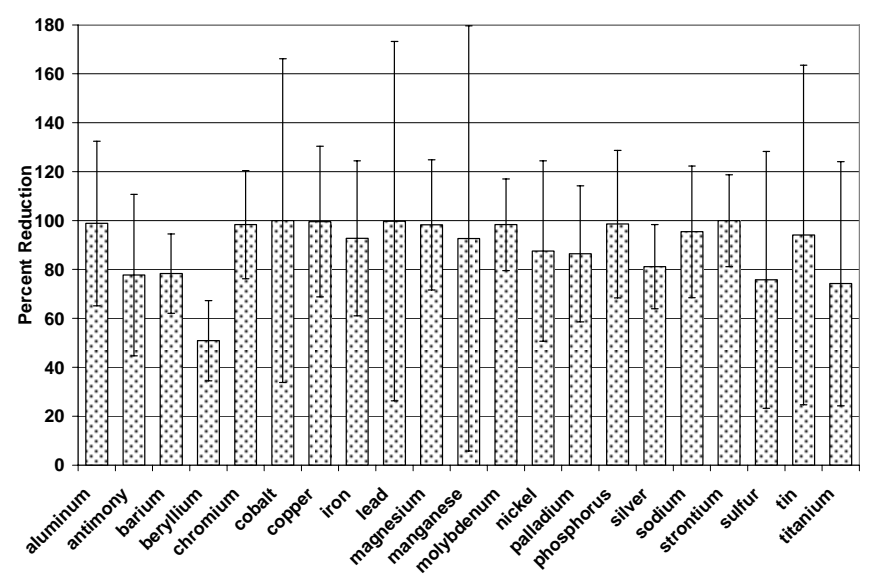

Figure 5. Percent Reduction of Trace Metallic Compound Emissions.

ORGANIC COMPOUNDS - A large variety of organic species were quantified in the present study. Particulate samples, collected on baked quartz filters, and gaseous samples, collected on PUF cartridges, TD tubes, and DNPH cartridges, were each analyzed for organic species. The samples were found to contain hopanes, steranes, aromatics, PAHs, aldehydes, and alkanes. The full results of the organic species analysis are discussed in the following sections.

Hopanes and Steranes - The high molecular weight, $\mathrm{C}_{27}$ to $\mathrm{C}_{33}$, compounds are typically considered to be derived from the engine lubrication oil $[8,9]$. The compounds analyzed in the present study included hopanes and steranes. Since these compounds are in the particle phase [7], it is unlikely that the DOC would have any effect on their emission rates unless exhaust temperatures were high enough for oxidation of these compounds to occur. Therefore, it is more likely that the reduction of these species, which was observed to be greater than $95 \%$, occurred due to particle filtration mechanisms over the CSF [1].

Polycyclic Aromatic Hydrocarbons and Aldehydes - The PAH compounds, which included $\mathrm{C}_{10}$ to $\mathrm{C}_{24}$ hydrocarbon species, are believed to be principally derived from diesel fuel $[8,9]$. As can be seen in Figure 6, the emission rates of these compounds were typically reduced by greater than $93 \%$, which most likely occurred through oxidation over the DOC and filtration through the CSF [1].

The greatest emission rates from the baseline engine were found for formaldehyde, acetaldehyde, and fluoranthene and its derivatives; however, each of these compounds was reduced by greater than $90 \%$ with the use the DPF aftertreatment system. Further, formaldehyde and acetaldehyde were each reduced to levels below the analysis detection limits. The significant reduction of the PAHs and the aldehydes is particularly important due to the potential carcinogenic properties that they possess [24]. 


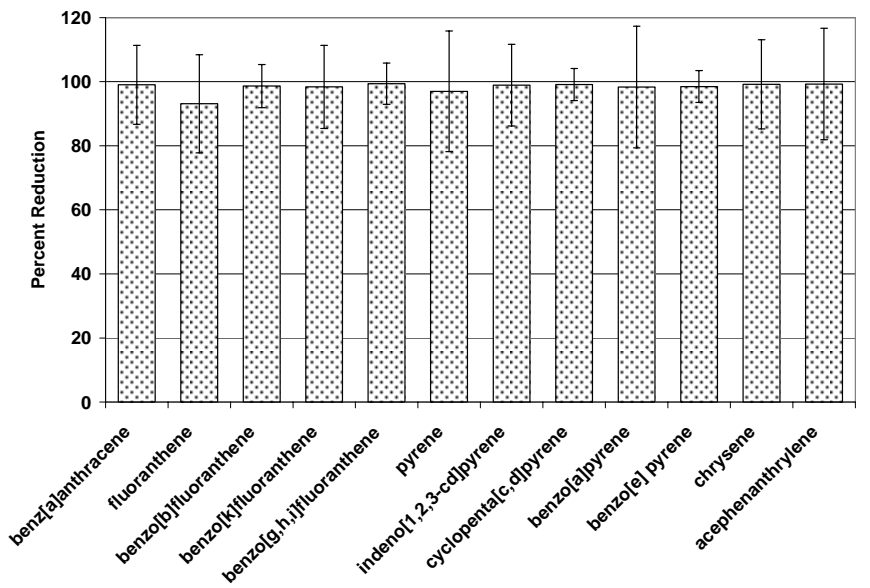

Figure 6. Percent Reduction through the DPF of Polycyclic Aromatic Hydrocarbon Emissions.

Aromatics - The low molecular weight aromatic compounds analyzed as part of the present study included chemical species such as benzene and styrene. These compounds are typically considered to be derived from the diesel fuel used to power heavy-duty diesel engines [8, 9]. The emission levels of these aromatic compounds were discovered to be reduced by greater than $97 \%$ after the inclusion of the DPF as can be seen in Figure 7. Due to their low carbon number, these compounds were most likely reduced through oxidation over the DOC $[8,9,25]$.

n-Alkanes - The remaining low carbon number organic compounds consisted primarily of $\mathrm{n}$-alkanes. The compounds classified as n-alkanes contained $\mathrm{C}_{12}$ to $\mathrm{C}_{22}$ species in the present study. These species have been observed in the emissions of diesel engine in the past and are thought to derive primarily from diesel fuel $[7,8$, 9]. Total emission levels for the n-alkanes were found to be reduced by greater than $88 \%$ with the use of the DPF aftertreatment system. Because of the low carbon number of the alkane compounds, their reduction is believed to be attributed to gas-phase oxidation over the DOC since it is not expected that adsorption onto the primary particles would be significant $[8,9,25]$. Additionally, emissions of branched alkanes and saturated cycloalkanes were observed from the test engine. These compounds, which ranged from $\mathrm{C}_{18}$ to $\mathrm{C}_{25}$, also displayed significant reductions, greater than $94 \%$ for the species analyzed.

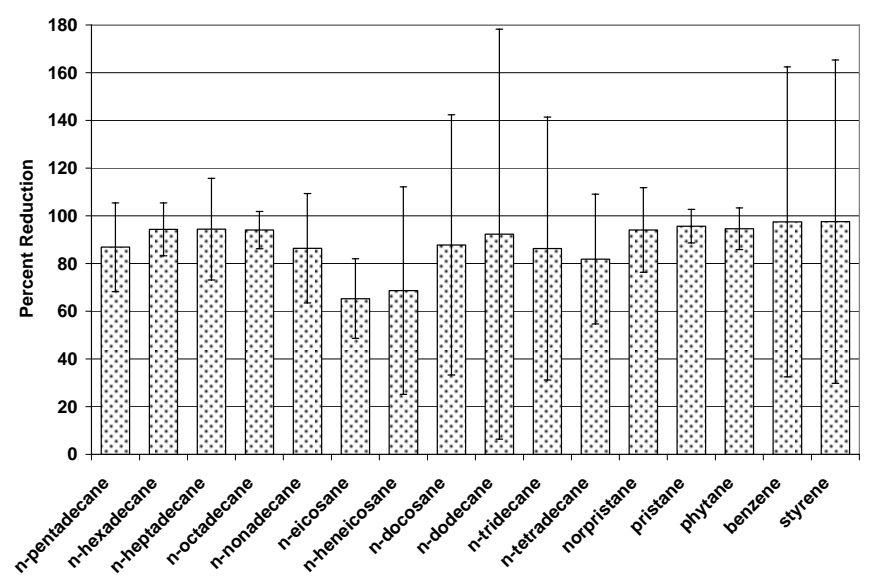

Figure 7. Percent Reduction of Alkane and Aromatic Emissions.

Summarized in Figure 8, the summed total of each group of organic compounds displayed significant reduction with the use of the DPF aftertreatment system. Due to the ultra-low emission rates of the chemical species, some of the compounds such as those in the alkane group displayed large errors associated with their measurement. Despite this, the majority of the compounds analyzed did show statistically significant reductions, based upon the standard error of the measurements, after the inclusion of the DPF aftertreatment system.

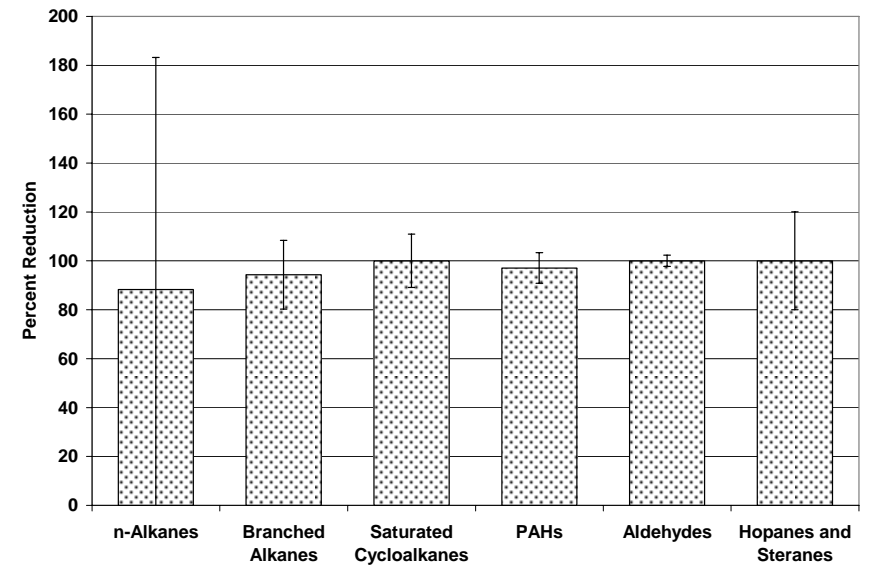

Figure 8. Organic Species Emissions Summary.

\section{CONCLUSIONS}

The results of the present study yield the following conclusions:

- The use of a diesel particulate filter significantly decreased the emitted levels of a large variety of chemical compounds.

- Not only was the test engine with DPF system capable of controlling the criteria pollutants, but 
the system was able to greatly reduce the emissions of unregulated species as well.

- The DPF aftertreatment system reduced the total particulate matter mass emissions by approximately 98\%. Correspondingly, similar reductions were observed for each of the major PM constituents including EC, OC, inorganic ions, trace metals, and organics.

- The largest contributing organic species were determined to be formaldehyde, acetaldehyde, and fluoranthene and its derivatives from the baseline engine. Significant reductions were observed for each of these compounds when using the DPF aftertreatment system.

- The species of toxicological concern, such as certain PAHs, formaldehyde, and acetaldehyde, were each reduced significantly. Although PAHs have the potential for formation during high temperature combustion processes, this effect was surpassed by the efficient oxidation and filtration of the DPF system.

\section{ACKNOWLEDGMENTS}

The authors acknowledge Dr. Roger McClellan, Prof. John Johnson and Prof. Susan Bagley of Michigan Technological University, Prof. David Foster of the University of Wisconsin-Madison, Dr. Barbara Zielinska of the Desert Research Institute, Prof. David Kittelson of the University of Minnesota, Dr. Doug Lawson of the National Renewable Energy Laboratory, and Dr. Glynis Lough of the U.S. EPA for their valuable discussions. We also acknowledge Dr. Wayne Eckerle of Cummins Inc., Thaddeus Swor, Victoria Vasys, Denise Ford, and Tom Wosikowski of Cummins Filtration and Emission Solutions for their help with sample collection, data analysis, or manuscript review as well as Jeff DeMinter, Steve Strebel, and Steve Geis of the Wisconsin State Laboratory of Hygiene for their help with the chemical analysis.

\section{REFERENCES}

1. Eastwood, P. Critical Topics in Exhaust Gas Aftertreatment, Research Studies Press Ltd., Baldock, 2000.

2. Zheng, M., G.T. Reader, and J.G. Hawley, "Diesel Engine Exhaust Gas Recirculation-A Review on Advanced and Novel Concepts," Energy Convers. Manage., 45, 883-900, 2003.

3. Suresh, A., A. Khan, and J.H. Johnson, "An Experimental and Modeling Study of Cordierite Traps - Pressure Drop and Permeability of Clean and Particulate Loaded Traps," SAE Paper No. 2000-01-0476, 2000.

4. Code of Federal Regulations. Protection of the Environment, Title 40, Parts 80 and 86; U.S. Government Printing Office: Washington, 2001.
5. Heck, R.M., and R.J. Farrauto, Catalytic Air Pollution Control: Commercial Technology, John Wiley \& Sons, Inc., New York, 1995.

6. Farrauto, R.J. and K.E. Voss, "Monolithic Diesel Oxidation Catalysts," Appl. Catal., B., 10, 29-51, 1996.

7. Schauer, J.J., M.J. Kleeman, G.R. Cass, and B.R. Simoneit, "Measurement of Emissions from Air Pollution Sources. 2. $\mathrm{C}_{1}$ to $\mathrm{C}_{30}$ Organic Compounds from Medium Duty Diesel Trucks," Environ. Sci. Technol., 33, 1578-1587, 1999.

8. Johnson, J.E. and D.B. Kittelson, "Physical Factors Affecting Hydrocarbon Oxidation in a Diesel Oxidation Catalyst," SAE Paper No. 941771, 1994.

9. Voss, K.E., T.D. Wildman, A. Gorel, M.G. Norris, T. Rotolico, and A. Fabel, "Zirconia Based Ceramic, InCylinder Coatings and Aftertreatment Oxidation Catalysts for Reduction of Emissions from Heavy Duty Diesel Engines," SAE Paper No. 970469, 1997.

10. Rogge, W.F., L.M. Hildemann, M.A. Mazurek, and G.R. Cass, "Sources of Fine Organic Aerosol. 2. Noncatalyst and Catalyst-Equipped Automobiles and Heavy-Duty Diesel Trucks," Environ. Sci. Technol., 27, 636-651, 1993.

11. ISO 8178-4, Reciprocating Internal Combustion Engines - Exhaust Emission Measurement Part 4: Test Cycles for Different Engine Applications, International Organization for Standardization, Geneva, 1996.

12. Liu, G.Z., T.A. Swor, J.J. Schauer, J. Debilzen, and C.A. Severance, "Source Dilution Sampling System for Characterization of Engine Emissions under Transient or Steady-State Operation," Aerosol Sci. Technol., accepted for publication, 2008.

13. Belyaev, S.P. and L.M. Levin, "Investigation of Aerosol Aspiration by Photographing Particle Tracks Under Flash Illumination," J. Aerosol Sci., 3, 127140, 1972.

14. Belyaev, S.P., and L.M. Levin, "Techniques for Collection of Representative Aerosol Samples," J. Aerosol Sci., 5, 325-338, 1974.

15. Birch, M.E. and R.A. Cary, "Elemental CarbonBased Method for Monitoring Occupational Exposures to Particulate Diesel Exhaust," Aerosol Sci. Technol., 25, 221-241, 1996.

16. Kolodziej, C., E. Wirojsakunchai, D.E. Foster, N. Schmidt, T. Kamimoto, T. Kawai, M. Akard, and T. Yoshimura, "Comprehensive Characterization of Particulate Emissions from Advanced Diesel Combustion," SAE Paper No. 2007-01-1945, 2007.

17. Seinfeld, J.H. and S.N. Pandis, Atmospheric Chemistry and Physics: from Air Pollution to Climate Change, John Wiley \& Sons, Inc., New York, 1998.

18. Schauer, J.J., G.C. Lough, M.M. Shafer, W.F. Christensen, M.F. Arndy, J.T. DeMinter, and J.S. Park, "Characterization of Metals Emitted from Motor Vehicles," Research Report 133, Health Effects Institute, Boston, 2006. 
19. Eller, P.M. NIOSH Manual of Analytical Methods, $4^{\text {th }}$ ed., U.S. Department of Health and Human Services, Cincinnati, 1994.

20. Winberry, W.T., S. Tejada, B. Lonneman, and T. Kleindienst, "Compendium of Methods for the Determination of Toxic Organic Compounds in Ambient Air," EPA/602/R-96/010b, 1999.

21. Durbin, T.D., X. Zhu, and J.M. Norbeck, "The Effects of Diesel Particulate Filters and a Low-Aromatic, Low-Sulfur Diesel Fuel on Emissions for MediumDuty Diesel Trucks," Atmos. Environ., 37, 21052116, 2003.

22. Warner, J.R., J.H. Johnson, S.T. Bagley, and C. Huynh, "Effects of a Catalyzed Particulate Filter on Emissions from a Diesel Engine: Chemical Characterization Data and Particulate Emissions Measured with Thermal Optical and Gravimetric Methods," SAE Paper No. 2003-01-0049, 2003.

23. Chatterjee, S., C. McDonald, R. Conway, H. Windawi, K. Vertin, C.A. LeTavec, N.N. Clark, and M. Gautam, "Emission Reductions and Operational Experiences With Heavy Duty Diesel Fleet Vehicles Retrofitted With Continuously Regenerated Diesel Particulate Filters in Southern California," SAE Paper No. 2001-01-0512, 2001.

24. Lloyd, A.C. and T.A. Cackette, "Diesel Engines: Environmental Impact and Control," J. Air Waste Manage. Assoc., 51, 809-847, 2001.

25. Bagley, S.T., L.D. Gratz, J.H. Johnson, and J.F. McDonald, "Effects of an Oxidation Catalytic Converter and a Biodiesel Fuel on the Chemical, Mutagenic, and Particle Size Characteristics of Emissions from a Diesel Engine," Environ. Sci. Technol., 32, 1183-1191, 1998.

\section{CONTACT}

Correspondence should be addressed to: Dr. Z. G. Liu at Cummins Emission Solutions, 1801 Highway 51-138, P.O. Box 428, Stoughton, WI 53589, jerry.z.liu@cummins.com.

\section{DEFINITIONS, ACRONYMS, ABBREVIATIONS}

CFV-CVS: Critical flow venturi-constant volume system
CSF: Catalyzed soot filter

DNPH: Dinitrophenylhydrazine

DOC: Diesel oxidation catalyst

DPF: Diesel particulate filter

EC: Elemental carbon

EGR: Exhaust gas recirculation

EPA: Environmental Protection Agency

GCIMS: Gas chromatography mass spectrometry

HC: Hydrocarbon

MSAT: Mobile source air toxic

NIOSH: National Institute of Occupational Safety and Health

$\mathrm{NO}_{\mathrm{x}}$ : Oxides of nitrogen

OC: Organic carbon

OM: Organic matter

PAH: Polycyclic aromatic hydrocarbon

PM: Particulate matter

POM: Polycyclic organic matter

PTFE: Polytetrafluoroethylene

PUF: Polyurethane foam

RTC: Residence time chamber

SOF: Soluble organic fraction

TD: Thermal desorption 